\title{
Antimicrobial Stewardship
}

\author{
ShIRA Doron, MD, AND Lisa E. DAVIDSON, MD
}

On completion of this article, readers should be able to: (1) describe the goals of antimicrobial stewardship and discuss why there is an increasing need for antimicrobial stewardship programs; (2) identify stewardship techniques that can be used in a variety of hospital settings by different health care practitioners; and (3) list steps for starting a stewardship program and identify potential barriers to implementation.

\begin{abstract}
Antimicrobial resistance is increasing; however, antimicrobial drug development is slowing. Now more than ever before, antimicrobial stewardship is of the utmost importance as a way to optimize the use of antimicrobials to prevent the development of resistance and improve patient outcomes. This review describes the why, what, who, how, when, and where of antimicrobial stewardship. Techniques of stewardship are summarized, and a plan for implementation of a stewardship program is outlined.
\end{abstract}

Mayo Clin Proc. 2011;86(11):1113-1123

ASP = antimicrobial stewardship program; $\mathbf{C l}=$ confidence interval; DDD = defined daily dose; $D O T s$ = days of therapy; ICU = intensive care unit; $\mathrm{OR}=$ odds ratio

\section{WHY DO WE NEED ANTIMICROBIAL STEWARDSHIP?}

In the early days of antibiotics, booming drug development meant that even when resistance developed, a new drug was always available to treat the increasingly resistant bacteria. Fourteen new classes of antibiotics were introduced between 1935 and 2003. However, rapid antimicrobial development came with a cost-antimicrobial resistance. In the hospital, resistance to antibiotics and antifungals poses the greatest concern. In 2003, US intensive care units (ICUs) reported to the Centers for Disease Control and Prevention that nearly 60\% of Staphylococcus aureus isolates were resistant to methicillin. ${ }^{1}$ Although the rate of invasive methicillin-resistant $S$ aureus infections in health care settings was shown to be decreasing in a 2010 Centers for Disease Control and Prevention study, ${ }^{2}$ isolates intermediately or overtly resistant to vancomycin are becoming less rare. ${ }^{3}$ Perhaps even more difficult to manage has been the increase in gram-negative resistance. ${ }^{4}$ Programs such as the international SMART (Study for Monitoring Antimicrobial Resistance Trend) ${ }^{5}$ and the SENTRY Antimicrobial Surveillance Program have shown substantial increases in the rate of Klebsiella resistance to third-generation cephalosporins, extended-spectrum $\beta$-lactamaseproducing Klebsiella pneumoniae and Escherichia coli, and Pseudomonas resistant to fluoroquinolones. ${ }^{1,6,7}$ During the past 30 years, antibiotic development has slowed con- siderably, and our options for treating increasingly resistant infections are becoming more and more limited. This review aims to describe the why, what, who, how, when, and where of antimicrobial stewardship.

Tens of thousands of Americans die of infections caused by antibiotic-resistant pathogens every year. Every day, patients die of bacterial infections for which no active agents are available. Yet since 1998 only 10 new antibiotics have been approved, only 2 of which (linezolid and daptomycin) actually have new targets of action. The reasons for this are simple: drug development is risky and expensive, and drugs to treat infections are not as profitable as those that treat chronic disease. Antibiotics currently in development are in existing classes and are broad spectrum in nature, which means they are likely to further promote the development of resistance if approved and used. In the hospital, an estimated $50 \%$ of antibiotic orders are unnecessary. ${ }^{8}$ It is in this setting that the broadest-spectrum antibiotics are being used, and rampantly. It is also in this setting that the most dangerous and extreme drug resistance has been seen. All of this has led the Infectious Diseases Society of America's Bad Bugs, No Drugs task force to call for a global commitment from stakeholders to support the development of 10 new drugs in novel classes by the year 2020. This so-called $10 \times 20$ initiative has been likened to John F. Kennedy's dream of walking on the moon.

\section{WHAT IS ANTIMICROBIAL STEWARDSHIP?}

Until this next giant step is achieved, those of us not developing new drugs have another job: conserve the antibiotics

From the Division of Geographic Medicine and Infectious Diseases, Tufts Medical Center, Boston, MA.

The authors have no conflict of interest to disclose.

Address correspondence to Shira Doron, MD, Division of Geographic Medicine and Infectious Diseases, Tufts Medical Center, 800 Washington St, Boston, MA 02111 (sdoron@tuftsmedicalcenter.org). Individual reprints of this article and a bound reprint of the entire Symposium on Antimicrobial Therapy will be available for purchase from our Web site www.mayoclinicproceedings.com.

(C) 2011 Mayo Foundation for Medical Education and Research 
we have. In the hospital, antimicrobial stewardship teams are charged with this important initiative. Antimicrobial stewardship has been defined as "the optimal selection, dosage, and duration of antimicrobial treatment that results in the best clinical outcome for the treatment or prevention of infection, with minimal toxicity to the patient and minimal impact on subsequent resistance." "The goal of antimicrobial stewardship is 3 -fold.

The first goal is to work with health care practitioners to help each patient receive the most appropriate antimicrobial with the correct dose and duration. Joseph and Rodvold ${ }^{10}$ wrote about the "4 D's of optimal antimicrobial therapy": right Drug, right Dose, De-escalation to pathogen-directed therapy, and right Duration of therapy. The optimal care of an infected patient means treating with the correct, properly dosed antibiotic and one that has the least likelihood of causing collateral damage (ie, leading to resistance in the patient or his or her contacts). An added benefit of programs that aim to optimize antibiotic use is that they generally experience cost savings because fewer doses of antibiotic are used and less expensive antibiotics are chosen. Comprehensive programs have demonstrated annual savings of $\$ 200,000$ to $\$ 900,000 .^{11-17}$

The second goal is to prevent antimicrobial overuse, misuse, and abuse. In both the hospital and the outpatient setting, physicians use antibiotics when they are not necessary. Antibiotics are given to patients with viral infections, noninfectious processes (a classic example is the febrile patient with pancreatitis), bacterial infections that do not require antibiotics (such as small skin abscesses that will resolve with incision and drainage), and bacterial colonization (as in the case of a positive urine culture result in a patient with a bladder catheter). Antibiotics are also frequently misused, such as in the very common scenario of the use of broad-spectrum antibiotics that cover multidrugresistant organisms in a patient whose infection was acquired in the community or the failure to adjust antibiotics according to culture data, thus maintaining the patient on a regimen to which the organism is not susceptible. Abuse of antibiotics is more difficult to define, but the term might be used to describe the use of one particular antibiotic preferentially over others by a physician as a result of aggressive detailing by the pharmaceutical representative or worse because of financial interest.

The third goal is to minimize the development of resistance. Both at the individual patient level and at the community level, antibiotic use changes susceptibility patterns. Patients exposed to antibiotics are at higher risk of becoming colonized or infected by resistant organisms. ${ }^{18-20}$ The most common cause of the development of Clostridium difficile diarrhea is exposure to antibiotics. ${ }^{21}$ Gram-negative resistance to carbapenems and cephalosporins has been shown to increase 10- to 20-fold with exposure to these broadspectrum antimicrobials. ${ }^{22-24}$ In a recent systematic review and meta-analyses of outpatient prescribing practices, the use of common antibiotics was associated with significant increased risk of development of antibiotic resistance, up to 12 months after antimicrobial exposure (pooled odds ratio [OR], 1.33; 95\% confidence interval [CI], 1.2-1.5). ${ }^{25}$ More importantly, antimicrobial resistance is associated with increased morbidity and mortality. Carbapenem-resistant $K$ pneumoniae is associated with an increased attributable mortality compared with sensitive Klebsiella (OR, 4.69; 95\% CI, 1.9-11.58; $P=.001)^{22}$ and methicillin-resistant $S$ aureus bacteremia, relative to methicillin-sensitive $S$ aureus bacteremia, has a significantly greater mortality risk as well (OR, 1.93; 95\% CI, 1.54-2.42; $P=.001) .{ }^{26}$ These resistant organisms can become transmitted to other individuals within the hospital or in the patient's community. Antimicrobial resistance also has significant hospital and societal costs. A recent study by Roberts et $\mathrm{al}^{27}$ estimated that the cost of an antimicrobial-resistant infection is $\$ 18,588$ to $\$ 29,069$ per patient, with an excess duration of hospital stay of 6.4 to 12.7 days and attributable mortality of $6.5 \% .{ }^{27}$

\section{WHO: BUILDING THE STEWARDSHIP TEAM}

Every hospital should work within its resources to create an effective team given its budget and personnel constraints. The stewardship team does not have to fit a particular mold, and it would be a mistake to delay implementation of a stewardship program because of a lack of availability of one or more of the typical team participants listed subsequently. Most stewardship teams include either an infectious disease physician or a pharmacist (with or without specialized training in infectious disease) or both. Sometimes a hospitalist with an interest in infectious disease serves in this role. Often the infection preventionist is an active member of the team. Close collaboration with the staff in the microbiology laboratory, hospital epidemiology, and administration is essential to a well-functioning program. A working relationship with the information specialist can be especially helpful. Engaging hospital leadership will open doors to good relationships with other physician groups. Therefore, early involvement of thought leaders from hospital administration and the various practitioner groups will improve acceptance and implementation.

\section{HOW: STEWARDSHIP STRATEGIES}

\section{Approaches}

There are 2 major approaches to antimicrobial stewardship, with the most successful programs generally implementing 
a combination of both. The front-end or preprescription approach to stewardship uses restrictive prescriptive authority. Certain antimicrobials are considered restricted and require prior authorization for use by all except a select group of clinicians. Clinicians without authority to prescribe the drug in question must contact the designated antimicrobial steward and obtain approval to order the antimicrobial. The frontend approach has the advantage of targeting specific antimicrobials for specific indications based on local resistance patterns and the hospital formulary. Antimicrobials can be approved for a specific duration, thereby prompting review after culture data have been obtained. Data suggest that programs that use this approach have been able to demonstrate significant reductions in expenditures of the targeted drug but also result in increased use of antimicrobials that are not restricted, ${ }^{28-30}$ which may or may not be the desired effect.

The back-end or postprescription approach to stewardship uses prospective review and feedback. The antimicrobial steward reviews current antibiotic orders and provides clinicians with recommendations to continue, adjust, change, or discontinue the therapy based on the available microbiology results and clinical features of the case. Studies of programs that use this approach have shown decreased antimicrobial use, decreased number of new prescriptions of antimicrobials, and improved clinician satisfaction. ${ }^{31,32}$ The back-end approach has the advantage of being able to focus on de-escalation, a critical aspect of appropriate antimicrobial use. De-escalation is modification of the initial empiric antimicrobial regimen based on culture data, other laboratory tests, and the clinical status of the patient. Deescalation includes changing a broad-spectrum antibiotic to one with narrower coverage, changing from combination therapy to monotherapy, or stopping antibiotic therapy altogether as it becomes more apparent that these drugs are not needed.

The newer rapid molecular diagnostic tests are designed to help clinicians de-escalate earlier in the antibiotic course. Peptide nucleic acid technology is widely available in the United States and allows for identification of common organisms from a positive blood culture within 90 minutes. Matrix-assisted laser desorption/ionization technology is gaining popularity in Europe and can be used to identify an increasing number of organisms from positive culture within 60 minutes. In one recent study, rapid polymerase chain reaction was used to differentiate methicillinresistant $S$ aureus bacteremia from methicillin-sensitive $S$ aureus in blood culture and the results provided immediately to an infectious disease pharmacist. During the period when this technology was being used, mean length of stay was 6.2 days shorter and mean hospital costs $\$ 21,387$ less for patients with $S$ aureus bacteremia. ${ }^{33}$ Other technologies are available and in development.
In addition to using one or both of these common approaches, comprehensive antimicrobial stewardship programs (ASPs) use a variety of other strategies and techniques to optimize antimicrobial use in the hospital.

\section{TECHNIQUES}

Formulary Restriction. Most hospitals have a formulary that is somewhat selective and does not include every available antimicrobial. The realities of the process of negotiating with pharmaceutical companies make this necessary because the price of the drug depends not only on how much of it the hospital uses but also on how little it uses of the competitor drug. As an example, most hospitals carry only one echinocandin antifungal. Formulary restriction is also a first step toward stewardship because, very simply, making only certain drugs available is a way to steer clinicians toward the use of those drugs. Formulary restriction can be a challenge for long-term acute care facilities that accept patients from multiple acute care hospitals with different formularies because they may feel an obligation to be able to offer the referring hospital continuation of the same antimicrobial the patient was receiving on transfer.

Order Sets and Treatment Algorithms. Order sets, whether on paper or as part of a computerized physician order entry system, can be an important tool in the stewardship team's efforts to ensure guideline-based appropriate empiric antibiotic ordering. Depending on the level of sophistication of the paper or electronic order set, the system can prompt the prescriber to make guideline-based antibiotic choices based on relevant clinical factors, to think about allergies, to remember to adjust for renal function, to consider the cost of therapy, and to order the appropriate tests, monitoring, and consultations. Hermsen et $\mathrm{al}^{34}$ used a surgical prophylaxis order form to improve antibiotic choices. This study demonstrated a significant increase in appropriate antimicrobial use, appropriate weight-based dosing, and appropriate duration of prophylaxis, as well as a decrease in the mean cost of antimicrobial prophylaxis. Treatment algorithms are similar decision tools but lack a direct interface with the ordering process. Some stewardship teams have even created pocket or online guidebooks for clinicians, which contain empiric antibiotic recommendations for common infections, dosing guidelines, and other helpful information.

Clinical Guidelines. One of the advantages of guideline development as part of an ASP is that it provides the opportunity to incorporate many thought leaders within a hospital to develop hospital- or network-specific algorithms. Guidelines can use national recommendations but should incorporate local trends in antimicrobial resistance and hospital-specific targets for decreased use. Ibrahim et $\mathrm{al}^{35}$ demonstrated that implementation of ventilator- 
TABLE 1. Novel Approaches to Antimicrobial Dosing to Combat Resistance

\begin{tabular}{|c|c|c|}
\hline Strategy and drug & Pharmacodynamically optimized dose & Reference(s) \\
\hline \multicolumn{3}{|l|}{ Prolonged infusion of $\beta$-lactams } \\
\hline Piperacillin-tazobactam & $3.375 \mathrm{~g}$ IV every $8 \mathrm{~h}$ for $4 \mathrm{~h}$ (prolonged infusion) & 42 \\
\hline Meropenem & $1 \mathrm{~g} \mathrm{IV}$ for $360 \mathrm{~min}$ every $6 \mathrm{~h}$ (continuous infusion) & 43 \\
\hline Doripenem & $500 \mathrm{mg}$ IV every $8 \mathrm{~h}$ for $4 \mathrm{~h}$ (prolonged infusion) & 44 \\
\hline \multicolumn{3}{|c|}{ Increased frequency dosing of quinolone } \\
\hline Ciprofloxacin & $400 \mathrm{mg}$ IV every $8 \mathrm{~h}$ & 45 \\
\hline \multicolumn{3}{|c|}{$\begin{array}{l}\text { Adjusting antimicrobial dosage to achieve } \\
\text { specific recommended blood level }\end{array}$} \\
\hline Vancomycin & $\begin{array}{l}\text { Maintain trough above } 10 \mathrm{mg} / \mathrm{L} \text { to prevent } \\
\text { development of resistance }\end{array}$ & $46-48$ \\
\hline \multicolumn{3}{|c|}{$\begin{array}{l}\text { Use of high-dose therapy to overcome } \\
\text { high MICs }\end{array}$} \\
\hline Cefepime & $2 \mathrm{~g} \mathrm{IV}$ every $8 \mathrm{~h}$ (3-h infusion) & 49 \\
\hline
\end{tabular}

associated pneumonia treatment guidelines during a 2-year period doubled the rate of appropriate initial therapy, while decreasing length of therapy and ventilator-associated pneumonia recurrence. Other studies of guidelines for ventilator-associated pneumonia, including at our own institution, have shown similar results. ${ }^{36-38}$ After an increase in $C$ difficile infections, the province of Quebec, Canada, initiated a global education program to reduce unnecessary antimicrobial use. ${ }^{39}$ Eleven guidelines were produced by a group of experts, sent to all physicians and pharmacists in Quebec, and posted on a dedicated Web site. Importantly, these guidelines were widely promoted throughout the province. After the guideline campaign, there were 4.1 fewer prescriptions per 1000 inhabitants (95\% CI, -6.6 to -1.6 ; $P<.002)$ and a decrease in prescription costs of $\$ 134.50$ per 1000 inhabitants (95\% CI, -270.5 to $1.6 ; P=.054$ ) in Quebec compared with the rest of Canada. These trends persisted 36 months later.

One of the advantages of using guidelines and clinical pathways for ASPs is the ability to reach out to frontline professionals who are not specialists in infectious disease. Jenkins et $\mathrm{al}^{40}$ recently published a study on the introduction of empiric therapy guidelines for uncomplicated cellulitis. The program targeted emergency department and general medicine physicians. Using this institutional guideline to standardize and streamline the evaluation of inpatient cellulitis resulted in a significant decrease in the use of microbiological and radiologic tests, a decrease in duration of antimicrobial therapy, and significant decreases in the use of broad-spectrum antimicrobials.

Education. All successful ASPs include an educational component. Clinicians are educated about the use of antimicrobials during the process of reading the order sets and treatment algorithms, during telephone conversations with the antimicrobial steward for the purpose of obtaining authorization for use of a restricted antimicrobial, during interaction with the antimicrobial steward conducting con- current review and feedback, and through formal didactic sessions or Grand Rounds-type lectures. At our institution, an Antimicrobial Management Team Question of the Week is sent by e-mail to all clinicians and has been very well received. In a recent study of pediatricians in Israel, the primary hypothesis was that a multifaceted intervention based on physicians' engagement with an education process that involved physician, parents, and child would result in longstanding reduction in antimicrobial resistance rates. ${ }^{41}$ Using a cluster randomized controlled design, the intervention group engaged physicians by conducting activities focused on self-developed guidelines, improving parent and physician knowledge, diagnostic skills, and parentphysician communication skills that promoted awareness of antibiotic resistance. Compared with the control group, a significantly greater decrease occurred in annual prescription rates in the intervention vs control group (relative risk, $0.89 ; 95 \%$ CI, 0.81-0.98), and the effect was sustained during the 4 following years.

Pharmacodynamic Dose Optimization. One stewardship technique that is being used with increasing frequency is pharmacodynamic dose optimization. Concepts, such as the pharmacodynamic parameter that is correlated with efficacy and knowledge of achievable tissue concentrations, guide the use of specific antimicrobials in previously unconventional and often off-label ways to optimize microbial killing and thus minimize the risk of promoting resistance. For $\beta$-lactam antibiotics, these dosing strategies maximize the percentage of time that the concentration of the unbound drug is above the minimum inhibitory concentration of the organism. Some of these dosing regimens are suggested by studies that use Monte Carlo simulation. Examples are given in Table 1.

Computer-Assisted Decision Support Programs. The rapidly increasing use of electronic medical records and computerized physician order entry systems provides a critical opportunity for both electronic surveillance of 
antimicrobial-prescribing practices and use of electronic systems to provide guidance to clinicians. Many decision support programs have been developed during the past few years to assist the antimicrobial stewardship team. These programs can identify allergies, inappropriate dosages, and, with the appropriate software and information technology systems, mismatches between drug and susceptibility. Evans et al ${ }^{50}$ demonstrated that one such model was able to provide physician feedback in a timely manner and resulted in significant reductions in the use of antimicrobials and length of stay. In a study conducted in Australia, a Web-based monitoring and approval system was used for cephalosporins. This system provided feedback on prescribing patterns to staff. Cephalosporin use decreased from 38.3 to 21.2 defined daily doses (DDDs) per 1000 patient-days after intervention. At the same time, concordance with national antibiotic guidelines increased. ${ }^{51}$ In a pediatric study, a Web-based automated clinical decision support tool provided real-time communication with prescribers of antibiotics. ${ }^{52}$ This system resulted in an $11.6 \%$ reduction in doses of antibiotics prescribed during 1 year and an increase in satisfaction of prescribers and pharmacists. The cost savings using this system was estimated at $\$ 370,069$.

Pharmacist-Driven Intravenous to Oral Switch Programs. Most clinicians cannot remember which medications are highly bioavailable, meaning that the oral formulation of these medications will achieve nearly the same blood level as the intravenous. For this reason many hospitals empower pharmacists to write orders to switch highly bioavailable antimicrobials (and other medications) from the intravenous to the oral formulation provided the patient meets certain criteria. Patients who are clinically stable and consuming a normal diet and other oral medications are automatically switched by pharmacy to oral drugs, saving money without detriment to the patient. Antimicrobials that are candidates for switch programs are summarized in Table 2.

Pharmacy Dosing Programs. In some hospitals, pharmacists are responsible for the dosing and monitoring of vancomycin and/or aminoglycosides. Often using electronic dose calculators, pharmacists are able to choose initial doses and adjust dosing based on levels with more accuracy to achieve appropriate subsequent blood levels compared with physicians who often base dose adjustments on techniques of estimation or at best use dosing nomograms. Bond and Raeh $l^{53}$ conducted a study evaluating outcomes in Medicare patients in hospitals with or without pharmacist-managed vancomycin or aminoglycoside dosing protocols. Those hospitals without pharmacist-managed protocols had higher mortality $(P<.0001)$, longer length of stay $(P<.0001)$, increased adverse events $(P<.001)$, and
TABLE 2. Highly Bioavailable Antimicrobials That Are Good Candidates for Intravenous to Oral Switch Programs

Fluoroquinolones (ciprofloxacin, levofloxacin, moxifloxacin)

Metronidazole

Macrolides (azithromycin, erythromycin)

Doxycycline

Clindamycin

Rifampin

Linezolid

Fluconazole

higher hospital costs $(P<.0001)$. One criticism of this type of program has been that clinicians, particularly resident physicians, will fail to learn or will forget how to dose these antibiotics if not practiced on a regular basis.

Antibiotic Cycling. Antibiotic cycling is the scheduled removal and substitution of specific antimicrobials or antimicrobial classes in a given patient care unit. The hypothesis is that by removing specific classes of antimicrobials on a regular basis, the development of resistance can be avoided. For example, all patients with suspected ventilator-associated pneumonia in a certain ICU might be treated with a fourth-generation cephalosporin in January, an antipseudomonal $\beta$-lactam/ $\beta$-lactamase inhibitor in February, and an antipseudomonal carbapenem in March; then the cycle is repeated. Studies of antimicrobial cycling are limited and heterogeneous. Several studies in ICU populations have demonstrated a decrease in ventilator-associated pneumonia due to multidrug-resistant infection with cycling. ${ }^{54,55}$ However, these studies also noted that cycling occurred in conjunction with de-escalation and an overall decrease in antimicrobial use. Therefore, it is difficult to ascertain whether the results were attributable to cycling or decreased use. Unfortunately, many trials of antimicrobial cycling are hampered by heterogeneous study populations and large percentages of patients receiving "off-cycle" antimicrobials. A recent systematic review was not able to conclude that cycling was beneficial. ${ }^{56}$ Because of insufficient data, the current Infectious Diseases Society of America guidelines on antimicrobial stewardship ${ }^{8}$ do not recommend antibiotic cycling.

Table 3 lists the most common antimicrobial stewardship approaches and techniques with their benefits and drawbacks and examples from the literature.

\section{STEPS TO TAKE WHEN IMPLEMENTING AN ASP}

\section{Understand Problem Pathogens and Antimicrobial Use at Your INSTITUTION}

An important first step in building an ASP should be to identify current institutional resistance patterns and an- 
TABLE 3. Summary of Antimicrobial Stewardship Techniques

\begin{tabular}{|c|c|c|c|c|}
\hline $\begin{array}{l}\text { Stewardship } \\
\text { approaches } \\
\text { and strategies }\end{array}$ & Description & Advantage & Disadvantage & Reference(s) \\
\hline $\begin{array}{l}\text { Front-end or } \\
\text { preprescription } \\
\text { authorization }\end{array}$ & $\begin{array}{l}\text { The antimicrobial steward reviews the } \\
\text { order for appropriateness at the time } \\
\text { it is written. Specific antimicrobials } \\
\text { are restricted to use by certain } \\
\text { prescribers or units, whereas others } \\
\text { must obtain authorization. Anti- } \\
\text { microbial order forms or order sets } \\
\text { can help prompt clinicians to obtain } \\
\text { approval }\end{array}$ & $\begin{array}{l}\text { Target antimicrobials that are } \\
\text { overused, misused, or abused } \\
\text { Encourage use of antimicrobials } \\
\text { based on hospital formulary } \\
\text { Lower antimicrobial costs } \\
\text { Useful in controlling outbreaks }\end{array}$ & $\begin{array}{l}\text { Unclear impact on anti- } \\
\text { microbial resistance } \\
\text { Some clinicians believe this } \\
\text { approach threatens their } \\
\text { autonomy } \\
\text { Acceptance of recommendation } \\
\text { may vary, depending on who } \\
\text { provides authorization } \\
\text { Transfer between facilities with } \\
\text { different formularies may } \\
\text { result in inappropriate } \\
\text { antimicrobial therapy } \\
\text { Loopholes in the system may } \\
\text { allow use of restricted } \\
\text { antibiotics without approval }\end{array}$ & $57-59$ \\
\hline $\begin{array}{l}\text { Back-end or } \\
\text { postprescription } \\
\text { prospective } \\
\text { review and } \\
\text { feedback }\end{array}$ & $\begin{array}{l}\text { The antimicrobial steward reviews } \\
\text { existing antibiotic orders and provides } \\
\text { clinicians with direct recommendations } \\
\text { to continue, adjust, change, or } \\
\text { discontinue the therapy based on the } \\
\text { available microbiology results and } \\
\text { clinical features of the case }\end{array}$ & $\begin{array}{l}\text { Direct interaction and } \\
\text { feedback with prescriber } \\
\text { Performed by a trained } \\
\text { antimicrobial steward } \\
\text { Frequency of intervention } \\
\text { can be tailored to size } \\
\text { of the institution }\end{array}$ & $\begin{array}{l}\text { Requires active surveillance by } \\
\text { an ASP, which is time- } \\
\text { consuming } \\
\text { May be difficult to perform } \\
\text { frequently in settings with } \\
\text { fewer resources }\end{array}$ & $\begin{array}{c}12,31,32 \\
60,61\end{array}$ \\
\hline $\begin{array}{l}\text { Clinical guidelines, } \\
\text { order sets, and } \\
\text { treatment } \\
\text { algorithms }\end{array}$ & $\begin{array}{l}\text { Prompt the prescriber to make evidence- } \\
\text { based antibiotic choices based on local } \\
\text { antimicrobial resistance patterns, } \\
\text { national guidelines, and relevant } \\
\text { clinical factors }\end{array}$ & $\begin{array}{l}\text { Can incorporate feedback } \\
\text { from multidisciplinary team } \\
\text { Can provide guidance for } \\
\text { de-escalation and appropriate } \\
\text { length of treatment }\end{array}$ & $\begin{array}{l}\text { Need to educate clinicians to } \\
\text { identify patients who are not } \\
\text { appropriate for specific } \\
\text { guidelines (eg, history of } \\
\text { MDR infection, } \\
\text { immunocompromised) }\end{array}$ & $35-38,40,62$ \\
\hline Education & $\begin{array}{l}\text { Grand Rounds, departmental } \\
\text { conferences, house staff teaching, } \\
\text { e-mail alerts, guidebooks }\end{array}$ & $\begin{array}{l}\text { Direct ASP to practitioner } \\
\text { interaction } \\
\text { Opportunity for focus on } \\
\text { particular ASP topics (CAP, } \\
\text { VAP, UTI, SSI, SCIP) }\end{array}$ & $\begin{array}{l}\text { Success depends on support of } \\
\text { administration, participation } \\
\text { of prescribers and clinical } \\
\text { staff }\end{array}$ & 39,41 \\
\hline $\begin{array}{l}\text { Pharmacodynamic } \\
\text { dose optimization }\end{array}$ & $\begin{array}{l}\text { Use of PK/PD properties of antimicrobial } \\
\text { agents to optimize drug efficacy based } \\
\text { on organism, site of infection, and } \\
\text { patient characteristics }\end{array}$ & $\begin{array}{l}\text { Optimal use of currently } \\
\text { available antimicrobials may } \\
\text { improve outcomes without } \\
\text { increased risk of toxic effects }\end{array}$ & $\begin{array}{l}\text { Education of nursing staff } \\
\text { regarding prolonged or } \\
\text { atypical administration }\end{array}$ & $42-45$ \\
\hline $\begin{array}{l}\text { Computer-assisted } \\
\text { decision support } \\
\text { programs }\end{array}$ & $\begin{array}{l}\text { Computer-based algorithm that guides } \\
\text { a practitioner and makes } \\
\text { recommendations for antimicrobial } \\
\text { regimens based on suspected infection, } \\
\text { patient characteristics, local } \\
\text { microbiology, and optimal drug dosing }\end{array}$ & $\begin{array}{l}\text { Can be incorporated into } \\
\text { existing CPOE based on } \\
\text { drug or suspected infection }\end{array}$ & $\begin{array}{l}\text { Requires significant time and } \\
\text { effort from information } \\
\text { technology services } \\
\text { May require additional training } \\
\text { of ASP team and prescribers }\end{array}$ & $50-52,63,64$ \\
\hline $\begin{array}{l}\text { Pharmacy-based } \\
\text { dosing programs }\end{array}$ & $\begin{array}{l}\text { Algorithms empower pharmacists to } \\
\text { transition bioequivalent drugs from IV } \\
\text { to PO formulation; dosing and } \\
\text { monitoring of vancomycin and } \\
\text { aminoglycosides }\end{array}$ & $\begin{array}{l}\text { Decreased length of stay and } \\
\text { early transition to oral } \\
\text { antimicrobials } \\
\text { Decrease physician error and } \\
\text { ordering of unnecessary levels }\end{array}$ & $\begin{array}{l}\text { Prescribers may quickly lose } \\
\text { comfort with appropriate } \\
\text { dosing and monitoring of } \\
\text { these potentially nephrotoxic } \\
\text { and ototoxic agents }\end{array}$ & 53 \\
\hline
\end{tabular}

$\mathrm{ASP}=$ antimicrobial stewardship program; $\mathrm{CAP}=$ community-acquired pneumonia; $\mathrm{CPOE}=$ computerized physician order entry; $\mathrm{IV}=$ intravenous; $\mathrm{MDR}=$ multidrug resistant; $\mathrm{PD}=$ pharmacodynamic; $\mathrm{PK}=$ pharmacokinetic $; \mathrm{PO}=$ oral; $\mathrm{SCIP}=$ surgical care improvement program; $\mathrm{SSI}=$ skin and soft tissue infection; UTI = urinary tract infection; VAP = ventilator-acquired pneumonia.

timicrobial use. Not all hospitals need the same level of interventions. Antimicrobial stewardship programs should be tailored to institutional problem pathogens and overuse of particular classes of drugs. Engage your microbiology laboratory, infection control, and pharmacy colleagues.

\section{Assess Your Current Resource}

Before funding can be secured for your ASP, it is crucial to understand what systems are in place that may be accessed to promote stewardship. First and foremost, many institutions have or are building electronic medical records and 
computerized physician order entry systems. These systems may be ideal places to begin development of guidelines and order sets. Many pharmacy purchasing systems may have the ability to track antimicrobial use and/or to record interventions. Educational forums, such as Grand Rounds or Lunch and Learns, may present opportunities for focus groups to discuss people's misconceptions and concerns about the idea of restricting antimicrobials. In addition, many national and international resources for stewardship have become available in recent months. The Centers for Disease Control and Prevention recently launched the Get Smart for Healthcare Web site and has many excellent resources for developing ASPs. ${ }^{65}$ The Infectious Diseases Society of America has guidelines on ASPs and support for clinical physicians developing a business plan..$^{8,66}$ Many centers that have ASPs have made their resources available online. ${ }^{67}$

Resources may also include current staffs that have an interest in developing a stewardship program. As noted, there is no set formula to determine who needs to be part of a stewardship program. Support and interest can be found from a wide range of practitioners at your institution.

\section{Determine Priority Areas and Plan for Interventions}

Once you have determined the current state of resistance and antimicrobial use in your institution and your current resources, you can begin to prioritize what areas need to be addressed. You can also begin to determine the most effective way of implementing change, for example, guidelines, order forms, guidebooks, electronic monitoring, and educational detailing. Identify what resources will be needed to fund these endeavors; can existing staff and technology be used or does a business plan need to be developed for funding of this program?

\section{Engage Hospital Leaders}

A key to establishing successful stewardship is the engagement of hospital leadership. Determining whether antimicrobial resistance and stewardship is important to hospital administration is a critical first step. If it is not, then you have ample opportunity to demonstrate why stewardship can improve safety and clinical outcomes and decrease antibiotic expenditures. If stewardship has not been a high priority, identifying an administrative "champion" who will support your case in discussion with the administration is extremely important. Antimicrobial resistance should be viewed as a quality and safety issue and can tie into many current safety campaigns and bundles, such as those focusing on community-acquired pneumonia, antimicrobial prophylaxis for surgery, and asymptomatic bacteriuria.

\section{Develop a Business Plan}

Developing a business plan might seem to be the most daunting part of developing an ASP. Start by determining your baseline expenditures. Then examine the attributable cost savings associated with the proposed interventions based on the literature and your own hospital data. For instance, if use of antibiotics targeting gram-negative bacteria for patients with uncomplicated skin and soft tissue infections is a problem at your institution, you can calculate the amount of drug saved if you were to implement an algorithm approach similar to that of Jenkins et $\mathrm{al}^{40}$ and assuming similar results. Overall, antimicrobial programs have been shown to be cost-effective. ${ }^{66}$ Determine the costs associated with the infectious disease diagnosis of interest. Costs may include not only the price of the antimicrobials but also those associated with laboratory tests and with adverse events from using the incorrect dose or type of antimicrobial. As an example, a simple and straightforward goal of any stewardship program can be implementation of a program for conversion of intravenous drugs to oral drugs. Oral drugs are usually less expensive and do not require placement of long-term intravenous catheters, minimizing complications from vascular access and enabling earlier discharge from the hospital.

Perhaps the biggest barrier to developing a stewardship program is the personnel cost. Many administrators see stewardship as part of the infectious disease consultant's job, and yet consultants are unable to bill for stewardship. There is currently no mechanism for direct reimbursement of stewardship programs, and therefore costs must be justified by demonstrating savings to the institution. Also, a widely held perception is that stewardship will result in a decreased number of consultations. In fact, stewardship programs should be aimed at augmenting and supporting the consultative service and may even result in an increased number of referrals.

\section{Put Your Plan Into Action}

Determine how you would like to roll out your ASP. Remember that the most successful plans incorporate educational outreach and physician feedback. If possible, survey hospital staff before and after each step of the program is implemented to determine practitioner satisfaction and room for improvement. Before implementation, identify what outcome data you would like to prospectively collect, such as practitioner satisfaction, antimicrobial use, expenditures, and clinical outcome variables, including readmission for specific conditions (eg, cellulitis and community-acquired pneumonia). Pharmacy purchasing systems usually track DDDs or days of therapy (DOTs), which are extremely useful measures of the success of the program. ${ }^{68}$ 
Measure your outcomes and incorporate feedback. It is important to have a predetermined timeline for assessment of goals and launching of each step of your ASP. Feedback on success and failure should be incorporated into the program on a regular basis. For each process implemented, there should be an outcome goal and measure. Antimicrobial consumption and expenditures are common outcome measurements, as discussed subsequently, but may not reflect other important goals, such as improved practitioner satisfaction, decrease in adverse drug events, improvement in adherence to Medicare or other quality measures, or changes in antimicrobial resistance.

The 2 most common methods used to evaluate drug consumption are DDD or DOTs. The DDD is calculated as the total number of grams of antimicrobial agent used divided by the number of grams in an average daily dose. The DDD is defined by the World Health Organization. ${ }^{69}$ The advantage of the DDD is the ability to compare standardized doses among hospitals. The disadvantage is that the DDD does not account for alternative dosing regimens due to renal dysfunction, age, or regimens that optimized pharmacokinetic or pharmacodynamic dosing. Therefore, in many cases the administered dose is different from the DDD recommended by the World Health Organization. This can result in either overestimation or underestimation of drug consumption. An alternative measurement is the number of DOTs. ${ }^{68}$ DOTs are expressed as the administration of a single agent on a given day regardless of the number of doses administered or dosage strength. The advantage is that DOTs are not affected by changes in dosing regimens. DOTs will not reflect actual doses and may not adequately represent antimicrobials that are administered multiple times daily. The DDD may be more helpful when benchmarking institutions or in large studies, whereas DOTs may be more helpful in comparing use of different classes of antimicrobials within an institution.

Many institutions begin implementing stewardship as a tiered program to improve practitioner comfort and acceptance. Philmon et $\mathrm{al}^{57}$ used a 3-tiered approach to introduce stewardship in a community teaching hospital in Dallas, TX: conversion from intravenous to oral administration for selected highly bioavailable antimicrobials, cessation of perioperative prophylaxis within 24 hours for patients undergoing clean and clean-contaminated surgery, and consultation with an infectious disease physician before continuing administration of selected drugs beyond 48 hours. From April 2001 through December 2003, a total of 1426 requests for antimicrobial therapy met criteria for intervention. Antimicrobial costs per patient-day decreased by $31 \%$, and total savings in acquisition costs were $\$ 1,841,203$. Significant decreases were found in Klebsiella resistance.
Soliciting practitioner feedback is a crucial step in the establishment of a successful stewardship program. We showed that house officer satisfaction with the stewardship program increased significantly between 2008 and 2010 after conducting a survey requesting feedback on the program and addressing their concerns by making programmatic changes. ${ }^{70}$

\section{WHERE CAN THINGS GO WRONG: BARRIERS AND PITFALLS}

One of the greatest challenges of antimicrobial stewardship research is demonstrating a clear causal association between implementation of ASPs and decreased rates of antimicrobial resistance. Early studies that achieved decreased cephalosporin use were successful in controlling the incidence of resistant gram-negative infections to cephalosporins but resulted in an increase in carbapenem use and resistance to carbapenems. ${ }^{71}$ This is an example of the "squeezing the balloon" phenomenon, in which decreasing use of one antimicrobial or class results in increasing use of another, often with associated resistance. Studies of outbreaks of $C$ difficile infections have shown improvement in infection rates with decreased use of cephalosporins and fluoroquinolones. ${ }^{72,73}$ These studies are encouraging in that they suggest that ASPs can impact the rate of $C$ difficile infections in hospitals. However, when such interventions come at the cost of increased use of extended-spectrum $\beta$-lactam/ $\beta$-lactamase inhibitors ${ }^{72}$ and carbapenems, other consequences may be experienced.

Studies of the implementation of antimicrobial stewardship and its effects on resistance are extremely difficult to control and are usually observational. One systematic review of the literature attempted to identify "rigorous evaluations" of interventions to improve hospital prescribing of antimicrobial drugs. Of the 16 studies that met criteria for inclusion, only 4 provided strong evidence that changes in prescribing antimicrobial drugs to hospital inpatients can decrease antimicrobial resistance. ${ }^{74}$ Four studies were negative, and the 8 remaining studies were cited as having flawed designs, allowing for alternative explanations for the outcome. Most studies of antimicrobial stewardship compare individual patient-level data points, such as antibiotic use and rates of colonization or infection with resistant organisms. Correlating the relationship between antimicrobial use and resistance over time may be more appropriate. Time-series analyses rely on aggregated, ecologic-level data and attempt to account for such variables as the introduction of infection control measures, the variation in use of broad-spectrum classes of drugs, colonization rates, and the lag time between implementation of interventions and development of resistance. In particular, time-series 
analysis is useful in study designs in which infection rates have been ascertained before and after an intervention, but controlling with a nonintervention group may not be practical or ethical. Several time-series analyses of methicillinresistant $S$ aureus and $C$ difficile have shown that variations in rates of multidrug-resistant infection may be attributed not only to changes in drug use but also to implementation of infection control practices and rates of colonization with multidrug-resistant bacteria. ${ }^{75-77}$

From a practical standpoint, implementing a stewardship program can seem like a monumental task. In a nationwide survey of hospitals, of 406 respondents, we found that $51 \%$ had what they would consider formal ASPs. Of those who did not, the most commonly cited barriers to implementation were staffing constraints, funding, and lack of time. ${ }^{78}$

\section{CONCLUSION}

As hospitalized patients become more complex to treat, the increasing prevalence of antimicrobial resistance in both health care and community settings represents a daunting challenge. With the increasing complexity of infections and a paucity of new antimicrobials in development, the future of successful antimicrobial therapy looks bleak. Antimicrobial stewardship can provide all practitioners with tools to prevent the overuse of valuable resources and help control the increase in antimicrobial resistance. Although often underappreciated, the increase of antimicrobial resistance has finally caught the attention of influential international health care organizations. The Institute of Medicine has identified antibiotic resistance ${ }^{79}$ as one of the key microbial threats to health in the United States and has listed decreasing the inappropriate use of antimicrobials as a primary solution to address this threat. The Get Smart campaign, initiated by the Centers for Disease Control and Prevention in 1995, focused on reducing the use of inappropriate antimicrobials in the outpatient setting. In 2010, the Centers for Disease Control and Prevention launched Get Smart for Healthcare, a campaign focused on improving antibiotic use in inpatient health care facilities to prevent overuse of antimicrobials and promote the use of antimicrobial stewardship. The 2011 World Health Organization World Health Day focused on international antimicrobial resistance. This World Health Organization campaign has drawn together agencies from all over the world to focus resources and combat the increase in antimicrobial resistance.

These organizations are drawing attention to the battles that practitioners face on a daily basis. This attention should be a call to action for insurance providers, national and state governments, and hospital administrators to provide much needed resources to practitioners who incorpo- rate stewardship practices into everyday patient care. The California Department of Public Health Antimicrobial Stewardship Initiative is an example of how government resources can be used to promote proper antibiotic use in health care facilities. California Department of Public Health staff assess existing stewardship practices at health care facilities to identify barriers to success and methods to overcome those barriers. They also provide consultative services to help facilities, including longterm care hospitals, where inappropriate antibiotic use is known to be especially common,$^{80}$ to assist in implementation of stewardship activities and development of formal programs. By making antimicrobial stewardship part of our daily practice, we can improve patient safety and care, reduce the unnecessary use of valuable resources, and reduce resistance.

\section{REFERENCES}

1. NNIS System; Division of Healthcare Quality Promotion, National Center for Infectious Diseases, Centers for Disease Control and Prevention, Public Health Service, US Department of Health and Human Services. National Nosocomial Infections Surveillance (NNIS) System Report, data summary from January 1992 through June 2003, issued August 2003. Am J Infect Control. 2003;31(8):481-498.

2. Kallen AJ, Mu Y, Bulens S, et al. Health care-associated invasive MRSA infections, 2005-2008. JAMA. 2010;304(6):641-648.

3. Hageman JC, Patel JB, Carey RC, Tenover FC, McDonald LC. Investigation and control of vancomycin-intermediate and -resistant Staphylococcus aureus (VISA/VRSA): a guide for health departments and infection control personnel. http://www.cdc.gov/ncidod/dhqp/pdf/ar/visa_vrsa_guide.pdf. 2006. Accessed September 7, 2011.

4. Kallen AJ, Srinivasan A. Current epidemiology of multidrug-resistant gram-negative bacilli in the United States. Infect Control Hosp Epidemiol. 2010;31(suppl 1):S51-S54

5. Rossi F, Baquero F, Hsueh PR, et al. In vitro susceptibilities of aerobic and facultatively anaerobic Gram-negative bacilli isolated from patients with intra-abdominal infections worldwide: 2004 results from SMART (Study for Monitoring Antimicrobial Resistance Trends). J Antimicrob Chemother. 2006;58(1):205-210.

6. Fridkin SK. Increasing prevalence of antimicrobial resistance in intensive care units. Crit Care Med. 2001;29(4)(suppl):N64-N68.

7. Jones RN. Resistance patterns among nosocomial pathogens: trends over the past few years. Chest. 2001;119(2)(suppl):397S-404S.

8. Dellit TH, Owens RC, McGowan JE Jr, et al. Infectious Diseases Society of America and the Society for Healthcare Epidemiology of America guidelines for developing an institutional program to enhance antimicrobial stewardship. Clin Infect Dis. 2007;44(2):159-177.

9. Gerding DN. The search for good antimicrobial stewardship. Jt Comm J Qual Improv. 2001;27(8):403-404

10. Joseph J, Rodvold KA. The role of carbapenems in the treatment of severe nosocomial respiratory tract infections. Expert Opin Pharmacother. 2008;9(4):561-575.

11. Schentag JJ, Ballow $\mathrm{CH}$, Fritz AL, et al. Changes in antimicrobial agent usage resulting from interactions among clinical pharmacy, the infectious disease division, and the microbiology laboratory. Diagn Microbiol Infect Dis. 1993;16(3):255-264.

12. Carling P, Fung T, Killion A, Terrin N, Barza M. Favorable impact of a multidisciplinary antibiotic management program conducted during 7 years. Infect Control Hosp Epidemiol. 2003;24(9):699-706.

13. LaRocco A Jr. Concurrent antibiotic review programs: a role for infectious diseases specialists at small community hospitals. Clin Infect Dis. 2003; 37(5):742-743.

14. Ansari F, Gray K, Nathwani D, et al. Outcomes of an intervention to improve hospital antibiotic prescribing: interrupted time series with segmented regression analysis. J Antimicrob Chemother. 2003;52(5):842848 
15. Rüttimann S, Keck B, Hartmeier C, Maetzel A, Bucher HC. Longterm antibiotic cost savings from a comprehensive intervention program in a medical department of a university-affiliated teaching hospital. Clin Infect Dis. 2004;38(3):348-356.

16. Lutters M, Harbarth S, Janssens JP, et al. Effect of a comprehensive, multidisciplinary, educational program on the use of antibiotics in a geriatric university hospital. J Am Geriatr Soc. 2004;52(1):112-116.

17. Scheckler WE, Bennett JV. Antibiotic usage in seven community hospitals. JAMA. 1970;213(2):264-267.

18. McGowan JE Jr. Antimicrobial resistance in hospital organisms and its relation to antibiotic use. Rev Infect Dis. 1983;5(6):1033-1048.

19. Monroe S, Polk R. Antimicrobial use and bacterial resistance. Curr Opin Microbiol. 2000;3(5):496-501.

20. Barbosa TM, Levy SB. The impact of antibiotic use on resistance development and persistence. Drug Resist Updat. 2000;3(5):303-311.

21. Kelly CP, LaMont JT. Clostridium difficile-more difficult than ever. $N$ Engl J Med. 2008;359(18):1932-1940.

22. Patel G, Huprikar S, Factor SH, Jenkins SG, Calfee DP. Outcomes of carbapenem-resistant Klebsiella pneumoniae infection and the impact of antimicrobial and adjunctive therapies. Infect Control Hosp Epidemiol. 2008; 29(12):1099-1106

23. Zaoutis TE, Goyal M, Chu JH, et al. Risk factors for and outcomes of bloodstream infection caused by extended-spectrum beta-lactamaseproducing Escherichia coli and Klebsiella species in children. Pediatrics. 2005;115(4):942-949.

24. Talon D, Bailly P, Bertrand $X$, Thouverez M, Mulin B; Reseau FrancComtois de Lutte contre les Infections Nosocomiales. Clinical and molecular epidemiology of chromosome-mediated resistance to third-generation cephalosporins in Enterobacter isolates in eastern France. Clin Microbiol Infect. 2000;6(7):376-384.

25. Costelloe C, Metcalfe C, Lovering A, Mant D, Hay AD. Effect of antibiotic prescribing in primary care on antimicrobial resistance in individual patients: systematic review and meta-analysis. BMJ. 2010;340:c2096.

26. Cosgrove SE, Sakoulas G, Perencevich EN, Schwaber MJ, Karchmer AW, Carmeli Y. Comparison of mortality associated with methicillin-resistant and methicillin-susceptible Staphylococcus aureus bacteremia: a meta-analysis. Clin Infect Dis. 2003;36(1):53-59.

27. Roberts RR, Hota B, Ahmad I, et al. Hospital and societal costs of antimicrobial-resistant infections in a Chicago teaching hospital: implications for antibiotic stewardship. Clin Infect Dis. 2009;49(8):1175-1184

28. Seligman SJ. Reduction in antibiotic costs by restricting use of an oral cephalosporin. Am J Med. 1981;71(6):941-944.

29. Britton HL, Schwinghammer TL, Romano MJ. Cost containment through restriction of cephalosporins. Am J Hosp Pharm. 1981;38(12):1897-1900.

30. Hayman JN, Sbravati EC. Controlling cephalosporin and aminoglycoside costs through pharmacy and therapeutics committee restrictions. Am J Hosp Pharm. 1985;42(6):1343-1347.

31. Solomon DH, Van Houten L, Glynn RJ, et al. Academic detailing to improve use of broad-spectrum antibiotics at an academic medical center. Arch Intern Med. 2001;161(15):1897-1902.

32. Fraser GL, Stogsdill P, Dickens JD Jr, Wennberg DE, Smith RP Jr, Prato BS. Antibiotic optimization: an evaluation of patient safety and economic outcomes. Arch Intern Med. 1997;157(15):1689-1694.

33. Bauer KA, West JE, Balada-Llasat JM, Pancholi P, Stevenson KB, Goff DA. An antimicrobial stewardship program's impact with rapid polymerase chain reaction methicillin-resistant Staphylococcus aureus/S. aureus blood culture test in patients with $S$. aureus bacteremia. Clin Infect Dis. 2010; 51(9): 1074-1080.

34. Hermsen ED, Smith Shull S, Puumala SE, Rupp ME. Improvement in prescribing habits and economic outcomes associated with the introduction of a standardized approach for surgical antimicrobial prophylaxis. Infect Control Hosp Epidemiol. 2008;29(5):457-461.

35. Ibrahim EH, Ward S, Sherman G, Schaiff R, Fraser VJ, Kollef MH. Experience with a clinical guideline for the treatment of ventilator-associated pneumonia. Crit Care Med. 2001;29(6):1109-1115.

36. Dellit TH, Chan JD, Skerrett SJ, Nathens AB. Development of a guideline for the management of ventilator-associated pneumonia based on local microbiologic findings and impact of the guideline on antimicrobial use practices. Infect Control Hosp Epidemiol. 2008;29(6):525-533.

37. Singh N, Rogers P, Atwood CW, Wagener MM, Yu VL. Short-course empiric antibiotic therapy for patients with pulmonary infiltrates in the intensive care unit: a proposed solution for indiscriminate antibiotic prescription. Am J Respir Crit Care Med. 2000;162(2, pt 1):505-511.
38. Lancaster JW, Lawrence KR, Fong JJ, et al. Impact of an institutionspecific hospital-acquired pneumonia protocol on the appropriateness of antibiotic therapy and patient outcomes. Pharmacotherapy. 2008;28(7):852 862 .

39. Weiss K, Blais R, Fortin A, Lantin S, Gaudet M. Impact of a multipronged education strategy on antibiotic prescribing in Quebec, Canada. Clin Infect Dis. 2011;53(5):433-439.

40. Jenkins TC, Knepper BC, Sabel AL, et al. Decreased antibiotic utilization after implementation of a guideline for inpatient cellulitis and cutaneous abscess. Arch Intern Med. 2011;171(12):1072-1079.

41. Regev-Yochay G, Raz M, Dagan R, et al. Reduction in antibiotic use following a cluster randomized controlled multifaceted intervention: the Israeli judicious antibiotic prescription study. Clin Infect Dis. 2011;53(1):3341.

42. Patel GW, Patel N, Lat A, et al. Outcomes of extended infusion piperacillin/tazobactam for documented Gram-negative infections. Diagn Microbiol Infect Dis. 2009;64(2):236-240.

43. Lorente L, Lorenzo L, Martin MM, Jimenez A, Mora ML. Meropenem by continuous versus intermittent infusion in ventilator-associated pneumonia due to gram-negative bacilli. Ann Pharmacother. 2006;40(2):219223.

44. Chastre J, Wunderink R, Prokocimer P, Lee M, Kaniga K, Friedland I. Efficacy and safety of intravenous infusion of doripenem versus imipenem in ventilator-associated pneumonia: a multicenter, randomized study. Crit Care Med. 2008;36(4):1089-1096.

45. Forrest A, Nix DE, Ballow CH, Goss TF, Birmingham MC, Schentag JJ. Pharmacodynamics of intravenous ciprofloxacin in seriously ill patients. Antimicrob Agents Chemother. 1993;37(5):1073-1081.

46. Rybak M, Lomaestro B, Rotschafer JC, et al. Therapeutic monitoring of vancomycin in adult patients: a consensus review of the American Society of Health-System Pharmacists, the Infectious Diseases Society of America, and the Society of Infectious Diseases Pharmacists. Am J Health Syst Pharm. 2009;66(1):82-98.

47. Rybak MJ, Lomaestro BM, Rotschafer JC, et al. Therapeutic monitoring of vancomycin in adults summary of consensus recommendations from the American Society of Health-System Pharmacists, the Infectious Diseases Society of America, and the Society of Infectious Diseases Pharmacists. Pharmacotherapy. 2009;29(11):1275-1279.

48. Rybak MJ, Lomaestro BM, Rotschafer JC, et al. Vancomycin therapeutic guidelines: a summary of consensus recommendations from the Infectious Diseases Society of America, the American Society of Health-System Pharmacists, and the Society of Infectious Diseases Pharmacists. Clin Infect Dis. 2009;49(3):325-327.

49. Nicasio AM, Ariano RE, Zelenitsky SA, et al. Population pharmacokinetics of high-dose, prolonged-infusion cefepime in adult critically ill patients with ventilator-associated pneumonia. Antimicrob Agents Chemother 2009;53(4):1476-1481.

50. Evans RS, Pestotnik SL, Classen DC, et al. A computer-assisted management program for antibiotics and other antiinfective agents. $N$ Engl J Med. 1998;338(4):232-238.

51. Richards MJ, Robertson MB, Dartnell JG, et al. Impact of a web-based antimicrobial approval system on broad-spectrum cephalosporin use at a teaching hospital. Med J Aust. 2003;178(8):386-390.

52. Agwu AL, Lee CK, Jain SK, et al. A World Wide Web-based antimicrobial stewardship program improves efficiency, communication, and user satisfaction and reduces cost in a tertiary care pediatric medical center. Clin Infect Dis. 2008;47(6):747-753.

53. Bond CA, Raehl CL. Clinical and economic outcomes of pharmacistmanaged antimicrobial prophylaxis in surgical patients. Am J Health Syst Pharm. 2007;64(18):1935-1942.

54. Raymond DP, Pelletier SJ, Crabtree TD, et al. Impact of a rotating empiric antibiotic schedule on infectious mortality in an intensive care unit. Crit Care Med. 2001;29(6):1101-1108.

55. Gruson D, Hilbert G, Vargas F, et al. Rotation and restricted use of antibiotics in a medical intensive care unit: impact on the incidence of ventilatorassociated pneumonia caused by antibiotic-resistant gram-negative bacteria. Am J Respir Crit Care Med. 2000;162(3, pt 1):837-843.

56. Brown EM, Nathwani D. Antibiotic cycling or rotation: a systematic review of the evidence of efficacy. J Antimicrob Chemother. 2005;55(1):69.

57. Philmon C, Smith T, Williamson S, Goodman E. Controlling use of antimicrobials in a community teaching hospital. Infect Control Hosp Epidemiol. 2006;27(3):239-244 
58. White AC Jr, Atmar RL, Wilson J, Cate TR, Stager CE, Greenberg SB. Effects of requiring prior authorization for selected antimicrobials: expenditures, susceptibilities, and clinical outcomes. Clin Infect Dis. 1997;25(2):230239.

59. Gross R, Morgan AS, Kinky DE, Weiner M, Gibson GA, Fishman NO. Impact of a hospital-based antimicrobial management program on clinical and economic outcomes. Clin Infect Dis. 2001;33(3):289-295.

60. Bantar C, Sartori B, Vesco E, et al. A hospitalwide intervention program to optimize the quality of antibiotic use: impact on prescribing practice, antibiotic consumption, cost savings, and bacterial resistance. Clin Infect Dis. 2003;37(2):180-186.

61. Cosgrove SE, Patel A, Song X, et al. Impact of different methods of feedback to clinicians after postprescription antimicrobial review based on the Centers For Disease Control and Prevention's 12 Steps to Prevent Antimicrobial Resistance Among Hospitalized Adults. Infect Control Hosp Epidemiol. 2007;28(6):641-646.

62. Hermsen ED, Shull SS, Puumala S, Rupp M. Improvement in prescribing habits and economic outcomes associated with the introduction of a standardized approach for surgical antimicrobial prophylaxis. Infect Control Hosp Epidemiol. 2008;29(5):457-461.

63. McGregor JC, Weekes E, Forrest GN, et al. Impact of a computerized clinical decision support system on reducing inappropriate antimicrobial use: a randomized controlled trial. J Am Med Inform Assoc. 2006;13(4):378384.

64. Cook PP, Rizzo S, Gooch M, Jordan M, Fang X, Hudson S. Sustained reduction in antimicrobial use and decrease in methicillin-resistant Staphylococcus aureus and Clostridium difficile infections following implementation of an electronic medical record at a tertiary-care teaching hospital. J Antimicrob Chemother. 2011;66(1):205-209.

65. Centers for Disease Control and Prevention (CDC). Get Smart for Healthcare Web site. Resources: state and local stewardship efforts. http://www.cdc.gov /getsmart/healthcare/improve-efforts/resources/index.html. Accessed September 7, 2011

66. McQuillen DP, Petrak RM, Wasserman RB, Nahass RG, Scull JA, Martinelli LP. The value of infectious diseases specialists: non-patient care activities. Clin Infect Dis. 2008;47(8):1051-1063.

67. Pagani L, Gyssens IC, Huttner B, Nathwani D, Harbarth S. Navigating the Web in search of resources on antimicrobial stewardship in health care institutions. Clin Infect Dis. 2009;48(5):626-632.

68. Polk RE, Fox C, Mahoney A, Letcavage J, MacDougall C. Measurement of adult antibacterial drug use in 130 US hospitals: comparison of defined daily dose and days of therapy. Clin Infect Dis. 2007;44(5):664-670.
69. WHO Collaborating Centre for Drug Statistics Methodology. Definitions and general considerations. http://www.whocc.no/ddd/definition_and_general _considera/. Accessed September 7, 2011

70. Hong SY, Lawrence K, Davidson LE, Taur Y, Nadkarni L, Doron S. Evaluation of programmatic changes to an antimicrobial stewardship program with house officer feedback [abstract 431]. Presented at Infectious Diseases Society of America 48th Annual Meeting; British Columbia, Canada; October 21-24, 2010. http://idsa.confex.com/idsa/2010/webprogram/Paper4082.html. Accessed September 7, 2011.

71. Rahal JJ, Urban C, Horn D, et al. Class restriction of cephalosporin use to control total cephalosporin resistance in nosocomial Klebsiella. JAMA. 1998;280(14): 1233-1237.

72. Valiquette L, Cossette B, Garant MP, Diab H, Pepin J. Impact of a reduction in the use of high-risk antibiotics on the course of an epidemic of Clostridium difficile-associated disease caused by the hypervirulent NAP1/027 strain. Clin Infect Dis. 2007;45(suppl 2):S112-S121.

73. Fowler S, Webber A, Cooper BS, et al. Successful use of feedback to improve antibiotic prescribing and reduce Clostridium difficile infection: a controlled interrupted time series. J Antimicrob Chemother. 2007;59(5):990-995.

74. Davey P, Brown E, Fenelon L, et al. Systematic review of antimicrobial drug prescribing in hospitals. Emerg Infect Dis. 2006;12(2):211-216.

75. Bosso JA, Mauldin PD. Using interrupted time series analysis to assess associations of fluoroquinolone formulary changes with susceptibility of gramnegative pathogens and isolation rates of methicillin-resistant Staphylococcus aureus. Antimicrob Agents Chemother. 2006;50(6):2106-2112.

76. Aldeyab MA, Monnet DL, Lopez-Lozano JM, et al. Modelling the impact of antibiotic use and infection control practices on the incidence of hospital-acquired methicillin-resistant Staphylococcus aureus: a time-series analysis. J Antimicrob Chemother. 2008;62(3):593-600.

77. Vernaz N, Hill K, Leggeat $\mathrm{S}$, et al. Temporal effects of antibiotic use and Clostridium difficile infections. J Antimicrob Chemother. 2009;63(6): 1272-1275.

78. Doron SI, Nadkarni LD, Lawrence KR, et al. National Antimicrobial Stewardship Practices-an update [abstract 370]. Presented at Society for Healthcare Epidemiology of America (SHEA) Annual Scientific Meeting; Dallas, TX; April 1-4, 2011.

79. Institute of Medicine. Microbial threats to health: emergence, detection, and response. Released March 15, 2003. http://iom.edu/Reports/2003 /Microbial-Threats-to-Health-Emergence-Detection-and-Response. Accessed September 7, 2011.

80. Strausbaugh LJ, Joseph CL. The burden of infection in long-term care. Infect Control Hosp Epidemiol. 2000;21(10):674-679.

\title{
The Symposium on Antimicrobial Therapy will continue in an upcoming issue.
}

\author{
This activity was designated for 1 AMA PRA Category 1 Credit(s). ${ }^{\mathrm{TM}}$
}

The contributions to the Symposium on Antimicrobial Therapy are a CME activity. For CME credit, see the link on our Web site at mayoclinicproceedings.com. 